\title{
Real Wages and Unemployment: State of the Debate
}

\section{Tom Valentine}

$\mathrm{T}$ he question of the impact of real wages on employment and unemployment continues to be contentious. A recent example is Bell (2000) in which a number of the essays touch on this question and related policy issues. Unfortunately, many of the essays use questionable arguments to sidestep the question altogether and this approach is consistent with a major strand in the Australian academic literature on unemployment. Therefore, it would be useful to restate the terms of this debate so that the arguments can be embedded in an appropriate framework. The second part of this paper attempts that task.

The third section of the paper examines two examples of sustained high unemployment rates that occurred in Australia in the twentieth century. In both cases, the high unemployment rate resulted from an attempt to improve the income distribution by increasing wage rates. An econometric analysis presented in the Appendix examines the role of high real wages in these experiences. In both cases the focus is on how the economy reacted to a real wage shock, that is, a sharp increase in real wages.

\section{The Debate}

The argument that high real wages increase the unemployment rate rests on the simple idea that when the cost of a particular factor of production increases, producers, all other things equal, will reduce the amount of that factor that they use. This impact of a wage increase will be aggravated by any tendency for higher real wages to increase the participation rate. In this sense there is very little to argue about. The one argument that has been made against this general position is that from a macroeconomic viewpoint, an increase in wages also represents an increase in income and therefore, presumably, in aggregate expenditure which would have a positive effect on employment. However, whatever evidence has been presented on this subject (usually in the form of macro-econometric models) has cast doubt on the claim that this effect offsets the direct effect of real wages on employment. One reason for this conclusion is that changing the income distribution against business profits reduces investment and aggregate expenditure and therefore creates unemployment.

Another argument against the significance of real wages in influencing unemployment is the relatively low elasticity of employment to real wages obtained in empirical studies (Junankar, 2000:99). Webster (2003) concludes that estimated elasticities range from -0.15 to about -0.80 . Assume that the actual elasticity is -0.50 and that the workforce is 10 million and employment is 9

Tom Valentine is Professor of Banking and Finance and Director of the Centre for Applied Finance in the College of Law and Business, University of Western Sydney. 
million. This means that a 10 per cent cut in the real wage would increase employment by 5 per cent to 9.45 million. However, unemployment is initially $1 \mathrm{~m}$ (that is, 10 per cent), and will fall by a much larger proportionate amount - to 550,000 (that is, a fall of 45 per cent) leaving aside any change that occurs in the participation rate. It can be shown that the elasticity of the unemployment rate with respect to real wages is equal to the elasticity of employment with respect to real wages multiplied by the ratio of employment to unemployment. In the above example, the elasticity is multiplied by 9 , making the elasticity of the unemployment rate 4.5. Note that this calculation assumes that the participation rate is not affected by the real wage rate. In view of these calculations, it not surprising that the econometric estimates reported below indicate that the unemployment rate is very sensitive to changes in real wages.

An alternative way of criticising the view that increasing real wages will increase unemployment is to point out that the market for labour is not a perfect market for a homogeneous commodity in which the price setting process cannot be regarded as a simple auction process (see Junankar, 2000). However, what market can be represented by such a simple model? This sensible empirical observation does not lead us in other cases to conclude that the price of a good (or a closely related set of goods) does not affect the quantity which is purchased. In the case of the labour market, investigators are free to analyse the special characteristics of that market. This analysis often takes the form of the development of special theories to explain certain aspects of the market. For example, the demand for different classes of labour can be examined. One factor affecting the demand for individual labour classes is the elasticity of the demand for the products that they produce which determines the extent to which consumers, rather than the workers concerned, bear an increase in wages. The insider-outsider theory explains how in some cases, unions (insiders) can prevent non-unionists (outsiders) from bidding down wages in their industries. Similarly, the theory of efficiency wages shows that some employers may pay higher wages because they believe that this policy will increase the productivity of their employees. Currently some writers are criticising the large rents being extracted by senior business executives and even by public servants in non-competitive situations. However, none of these special characteristics of the labour market contradicts the general principle that, all other things equal, higher real wages will lead to a higher unemployment rate.

Of course, all things might not be equal. Governments have numerous policies available to them to reduce unemployment and to offset an increase in the real wage. For example, they can provide training programs or they can adjust the structure of social security rules to encourage employment. Most importantly, they can use stimulatory monetary or fiscal policies to increase aggregate expenditure. In particular, they can engage in public works, which directly create jobs. The latter approach has become unfashionable in recent times, but there is no reason to doubt its short-term effectiveness. There seems to be little actual economic analysis behind the 'surplus fetish' adopted by both the major political parties in Australia, which inhibits the adoption of public works programs. This 
view unnecessarily restricts a government's flexibility in responding to a recession. There is no reason for a government not to run a budget deficit from time to time. The arguments for 'public works' are canvassed in Nevile (2000). Quiggin (2000) goes further and argues for higher average tax rates to finance increases in jobs in the intensive human service sector and infrastructure expenditure. Quiggin's point that Australia is a low tax country is correct although recent media discussion may make it appear to be controversial. It may well be that the Australian population should reconsider its decision in favour of low taxation and low levels of government services. The effects of governmental neglect of infrastructure are becoming increasingly obvious and there is a good argument for initiatives in this area. However, Quiggin's suggested taxation reforms certainly need further consideration. Also, specific programs to expand the human services sector may be unnecessary. Wagner's Law suggests that there is a natural tendency for the supply of government services to increase as national income expands. Henry (2003) suggests that the government share of GDP will increase into the future, but his reasons for this conclusion should be carefully considered.

These arguments have been canvassed by Junankar (2000) in the context of answering the question of whether wage cuts are an effective policy to reduce unemployment. However, many writers concerned with the impact of real wages on unemployment are not advocating wage cuts. Rather they are concerned about the effect of a 'wages shock' - a sharp increase in wages with the intention of creating a more equitable income distribution. How the economy reacts to such a shock is analysed in the empirical work reported below. The results suggest that it takes some time for a wage shock to be absorbed and for the unemployment rate to return to its original level.

The policy implications of the relationship between real wages and the unemployment rate depends on the regulatory environment. This point can be clarified by considering two extreme cases:

(i) The government or an independent arbitrator sets a minimum wage rate which is largely reflected in average earnings. In this case it makes sense to talk about wage-setting policy.

(ii) There is no minimum or award wage rate and real earnings are an endogenous variable determined within the economic system. In this case (close to the current situation in Australia) it is not meaningful to talk about a wage-setting policy. However, it may be possible to introduce labour market reforms (such as the introduction of enterprise agreements) that improve employment outcomes. Moreover, more general microeconomic reform (including the adoption of a floating exchange rate regime) might improve the productivity of workers and thereby increase the level of employment.

In order to understand the latter point, it is important to note that, stating the basic principle more precisely, employment depends on real unit labour cost (RULC) rather than the real wage. Now, 


$$
\begin{array}{ll}
\text { RULC } & =\frac{\mathrm{WxE}}{\mathrm{PxRY}} \\
\text { where } \quad \mathrm{W} & =\text { average earnings; } \\
\mathrm{E} & =\text { employment } \\
\mathrm{P} & =\text { the price level } \\
\mathrm{RY} & =\text { real output }
\end{array}
$$

Therefore,

$$
\begin{aligned}
& \text { RULC }=\frac{\mathrm{W} / \mathrm{P}}{\mathrm{RY} / \mathrm{E}}=\frac{\mathrm{RW}}{\mathrm{PROD}} \\
& \text { where } \quad \mathrm{RW}=\text { real average earnings } \\
& \mathrm{PROD}=\text { labour productivity } \\
& \text { Now, } \frac{\mathrm{dRULC}}{\mathrm{dt}}=\frac{\mathrm{RW}}{\mathrm{PROD}}\left[\frac{1}{\mathrm{RW}} \frac{\mathrm{dRW}}{\mathrm{dt}}-\frac{1}{\mathrm{PROD}} \frac{\mathrm{d} \text { Prod }}{\mathrm{dt}}\right]
\end{aligned}
$$

This relationship can be rewritten:

Proportional Increase in Real Unit Labour Costs $=$ Proportional Increase in Real Wages - Proportional Increase in Productivity

Therefore, any reform that increases productivity will reduce RULC and, other things equal, will lead to employment growth. Australia had a strong productivity performance over the last two decades of the twentieth century, but this led to only a modest fall in RULC because most of the increase in productivity was passed on in higher real wages. This is indicated by the following equation for the period 1981 to 2001 .

$$
\begin{aligned}
& \Delta \% \mathrm{RW}=-0.303+1.037 \Delta \% \mathrm{PROD} \quad \overline{\mathrm{R}}^{2}=0.295 \\
& (0.45) \quad\left(3.06^{* *}\right) \\
& \mathrm{d}=2.15
\end{aligned}
$$

The wage variable used in the above equation is the total compensation of employees divided by the number of employees. It therefore includes non-wage costs such as compulsory superannuation contributions. Freebairn (2003) shows 
that the impact of the Superannuation Guarantee Charge on employment and wages depends on its impact on labour supply, which in turn depends on the extent to which workers regard the superannuation payment as a substitute for a wage payment. The coefficients in this equation are very stable over the estimation period. Wooden (2003) presents evidence to show that prior to 1996 workers tended to supplement their earnings by increasing their hours of work in one way or another. After 1996, they were able to obtain wage increases in line with increases in productivity because of the extension of enterprise bargaining. The measures of earnings and productivity used in the above equation do not take account of changes in the average hours worked by workers. Therefore, the results provide some support for Wooden's hypothesis.

Productivity has been defined here as output per worker. Productivity in this sense will be increased by investment, which increases the amount of capital per worker. In some periods wages have been increased in line with the change in productivity, which some commentators argue is an equitable way to fix wages. If this is done, unit labour costs will be unchanged and consequently the price level and real unit labour costs will also be unchanged. Therefore, there will be no wage effect on the unemployment rate (that is, the increase in the amount of capital will not reduce the unemployment rate). It should be noted, however, that this conclusion depends on the assumption that the unemployment rate depends on real unit labour costs and that the price level depends on unit labour costs.

Moreover, the return on capital remains constant. As Valentine (1993) points out this may reduce the incentive for investment (which would increase national income and therefore reduce the unemployment rate) relative to the situation that would exist if wages were market determined.

The effectiveness of microeconomic reform has been criticised by some of the authors in Bell (2000), particularly Gregory (2000), by comparing the performances of countries that are deemed to have undergone significant reform with those of countries which have experienced less change. This approach creates inappropriate counterfactuals. It takes no account of the other factors affecting the performances of the various countries and does not adopt the normal approach in economic research of attempting to remove the effects of other variables before considering the relationship between two variables. It is interesting that economists of the School represented in Bell (2000) often cite the success of the Norwegian economy as an example of a country that has successfully withstood deregulation without mentioning the word 'oil'. Quiggin (2000:221) does modify his view of the Norwegian success (as compared with the performance of Sweden which has undergone considerable reform) by throwing in the phrase 'partly because of the availability of revenue from North Sea oil', but he pays no further attention to this significant variable.

Also, the approach ignores the initial conditions for the countries involved in the comparisons. In particular, countries will often undertake fundamental economic reforms only when they are already in serious economic difficulties. The only appropriate counter-factual (although a difficult one to create) is what would have happened to the country if the reforms had not been introduced. Also, 
reforms do not have an immediate effect and the time elapsed needs to be considered.

Parham (2002) argues that Australia experienced an increase in the rate of productivity growth of over 1 percentage point in the 1990s. He attributed this increase to microeconomic reforms. Quiggin (2001) argues that the productivity gains have been exaggerated although his estimates still indicate some productivity gains. Quiggin (2001) quotes Krugman (1998) as describing "Australia as the "miracle economy of the financial crises", , but argues that this comment referred to macroeconomic management rather than microeconomic reform. However, macroeconomic management includes the floating of the Australian dollar which has had an important effect on the competitiveness of the Australian economy.

\section{Two Examples of High Unemployment}

There were two major bouts of unemployment in Australia in the twentieth century, specifically in:

- $\quad$ the thirties (the Great Depression); and

- the last 25 years of the $20^{\text {th }}$ Century.

In both cases the analysis can proceed in terms of wage-setting policy. As will be seen, in both cases the relevant authorities increased award wages sharply and this led to an increase in real unit labour costs. The result was higher unemployment.

How does the economic system react to this increase in award wages? The natural reaction is for prices to increase so that the real wage and real unit labour cost return to their original level and the unemployment rate returns to something close to its original level. Under this view prices are set as a mark-up over labour costs.

However, this adjustment process is retarded by a number of factors. First, there is a long lag in the adjustment of prices to changes in unit labour costs. Secondly, the extent to which prices can be increased depends on the strength of aggregate demand. The high unemployment rate created by the initial wage shock will create an environment unfavourable to increasing prices. Thirdly, monetary authorities are likely to institute policies which contain inflation, that is, prevent the price changes that are necessary to allow the economic system to adjust to the changes in wage levels.

The workings of the adjustment process are illustrated by the econometric models reported in the Appendix. The results can be summarised as follows:

- in both cases, the economy had a 'real wage overhang' at the beginning of the period;

- there is a significant lag in the reaction of prices to changes in wages; and 
- in the earlier period, increases in wages (unit labour costs) are not fully reflected in prices and in both cases, the effect of the increase in real wages has not worked off by the end of the period.

It has to be recognised that the outcome of an increase in real wages depends on the environment in which it occurs. Specifically, it depends on the institutional and regulatory structure of the economy, the stance of monetary and fiscal policy, the exchange rate regime and the strength of exports. The first influence may explain why the models for the two periods include different equations. A further explanation is the difference in data availability. Also, there is a possibility that the reaction of the economy to a change in wages depends on its size or its sign. This second question has not been investigated in the econometric analysis presented in the Appendix. These possibilities provide opportunities for future research

\section{Conclusion}

The discussion of policies on unemployment needs to be adapted to the environment in which the discussion is taking place. If the authorities have an important influence on average earnings by fixing minimum (or award) wages, it makes sense to discuss the merits of alternative wages policies. If earnings are determined endogenously, other policies need to be considered. Such policies include those directly targeted on unemployment, but they should also include general measures of economic reform. Employment creation is one of the aims of microeconomic reform and we need to analyse its successes or failures in this area. It is not sufficient to simply reject it on the basis of a few general and unsoundly based comparisons.

The econometric results discussed in the Appendix to this paper show that when the authorities can control wage rates, they need to be very careful to ensure that this control is not used to create unemployment. Specifically, attempts to modify income distribution by sharply increasing wage rates are likely to lead to a higher unemployment rate and to be eroded over time by increasing prices. These results are relevant in the evaluation of any proposals to return to a centralised system of wage fixation.

\section{Appendix}

\section{The Depression Experience}

In 1920, 1921, 1922 there were sharp increases in minimum wages, which carried through into average weekly earnings. In part, this increase was based on past inflation, but it overshot the amount necessary to provide adequate compensation for the earlier price increases. RULC increased by over 20 per cent between 1918-19 to 1921-22 and remained at that higher level over the nineteen twenties. 
This means that Australia had a 'wages overhang' (an accumulation of wage increases in excess of productivity gains) in the nineteen twenties and this overhang was carried through into the depression period. This conclusion contradicts that of Gregory, Ho and McDermott (1988:244) that 'real wage gaps' were not relevant to explaining unemployment during the depression.

The adjustment process is represented by the econometric model in Table A.1. The data used in estimating the model was obtained from Butlin (1977). The first equation explains the unemployment rate in terms of the real average wage rate and real gross national product. The second equation explains the price level as a mark-up over unit labour costs. However, the markup is a function of the strength of aggregate demand. In this case aggregate demand is measured by the unemployment rate itself. Both equations include a lag in adjustment. The model explains the unemployment rate rather than employment because determining a variable in a model as the difference between two other variables can lead to large errors.

The equation for the unemployment rate includes a time trend to account for the effect of technological progress on employment and the unemployment rate. Not surprisingly, its coefficient is positive in both models.

Most of the variables used in estimating this model are integrated to order 1. In these circumstances any estimated relationship could be spurious. However, there may be a co-integrating relationship amongst the variables, that is, a longterm relationship in which the estimated residuals are integrated of order zero. There are a number of approaches to this problem (see Davidson and Mackinnon, 1993:Chapter 20), but the one adopted in this paper is to test the residuals for the presence of a unit root (that is, to ensure that they are of order zero). This was done by using the Augmented Dickey-Fuller statistic, but with significance levels taken from Table 20.2 of Davidson and Mackinnon (1993), which applies to regression residuals. For both the estimated equations we were able to reject the null hypothesis that the residual series contained a unit root.

The first two equations in Table A.1 have been estimated by the Seemingly Unrelated Regressions (SUR) technique, which uses the correlation between the errors in the equations to improve the efficiency of the estimates.

In this case the correlation coefficient of the residuals in the equations is 0.342 indicating that efficiency gains were achieved by using the SUR estimator. Dummy variables have been included to remove some outliers amongst the regression residuals. These outliers could have arisen from problems in the original data.

The price equation shows that prices do increase when unit labour costs increase but that the reaction of prices is subject to a significant lag and adjustment is retarded by the reduction in demand as reflected in the unemployment rate. Moreover, the long-run elasticity of prices to unit labour costs $(0.852)$ is significantly less than unity 
Table A.1: A Simple Model of Unemployment 1900-1939

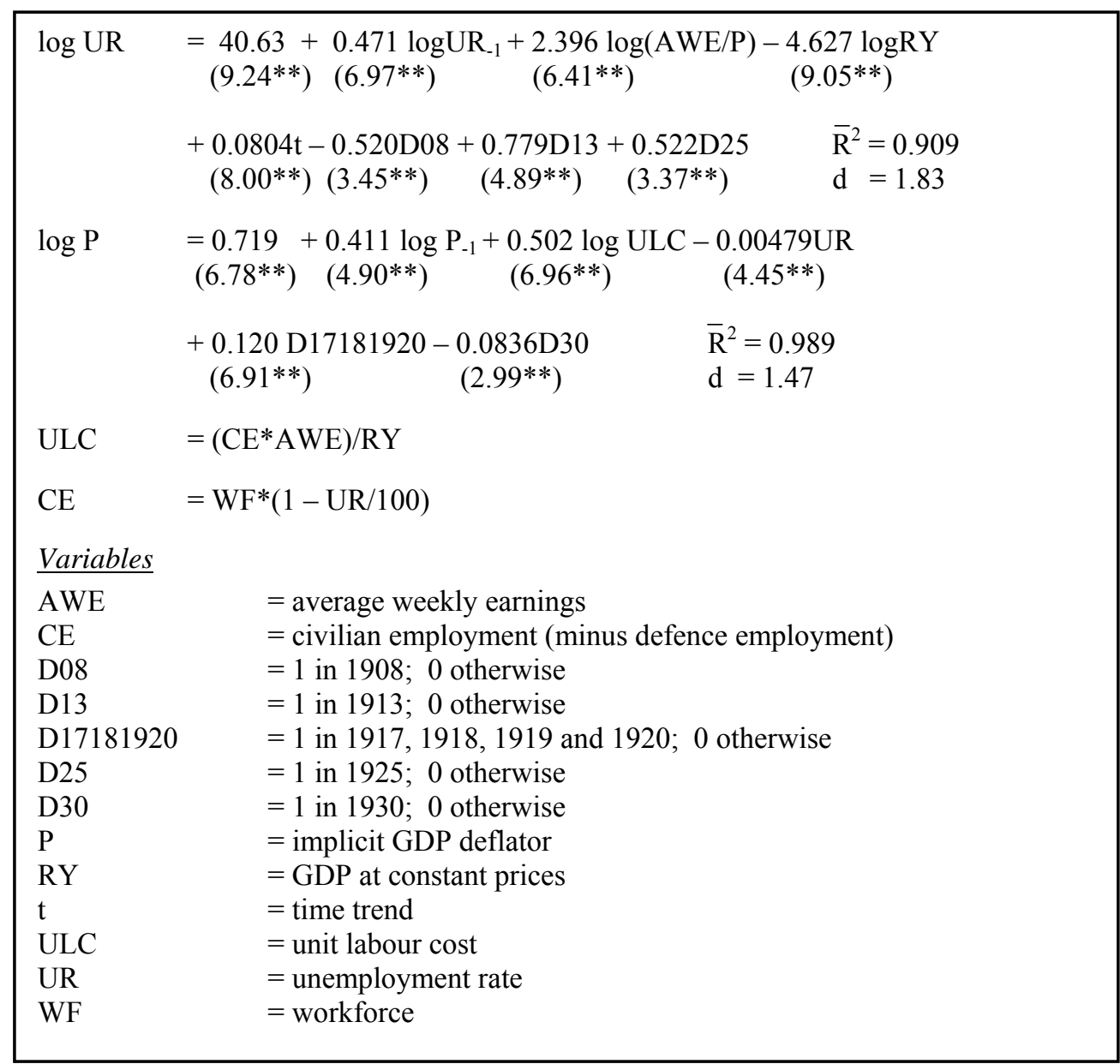

Figure A.1 indicates the results of various dynamic simulations of the model in Table A.1. UR is the original series and UR* is the result of a dynamic simulation of the model using the original data. This is a test of the model's ability to track the economy. The correlation between UR and UR* is 0.920 , indicating that the model gives a good explanation of the data.

$\mathrm{UR}^{* *}$ is the result of a dynamic simulation in which AWE was reduced by $10 \%$ over the period 1920 to 1939 . Up until 1919 the values of UR* and UR** are the same. It is clear that this reduction in wages would have substantially lowered the unemployment rate in both the nineteen twenties and the nineteen thirties. Also, the effect of the reduction was not exhausted, even at the end of the thirties.

The conclusions are similar to those produced by the econometric model in Valentine (2003). 
Figure A.1: Simulations of a Model of Unemployment 1901 - 1939

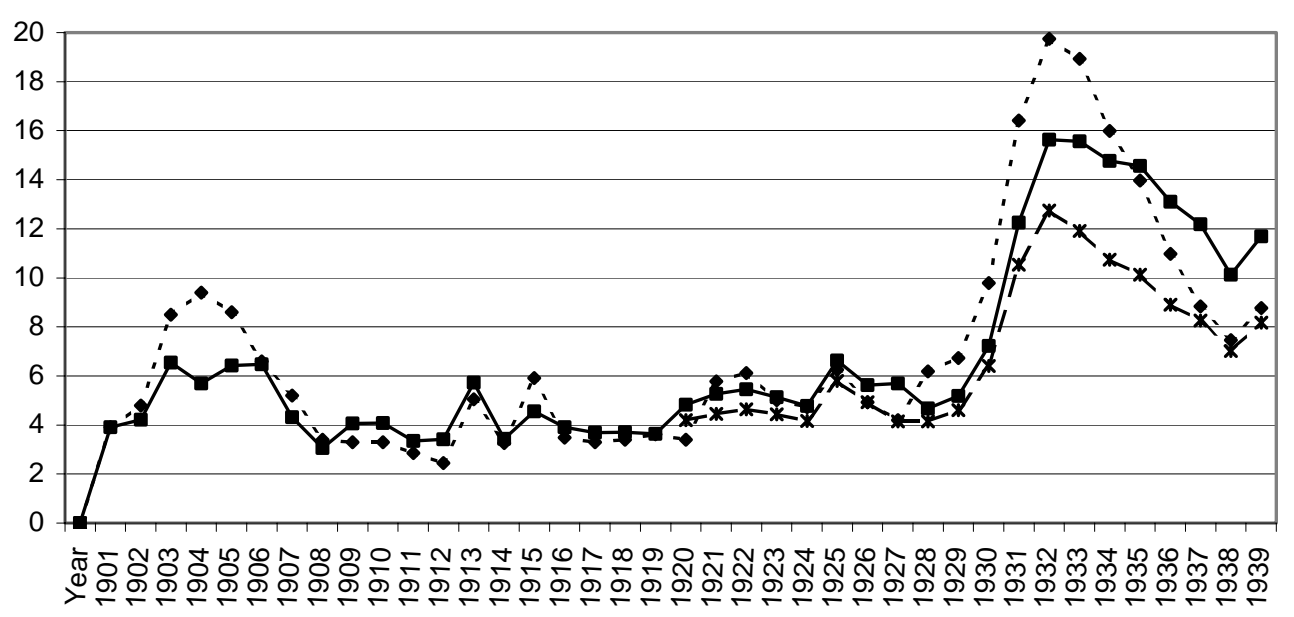

$\mathrm{UR}$..... $\mathrm{UR}^{*} \longrightarrow \mathrm{UR}^{* *}$ —

\section{Unemployment 1980 to 2001}

Table A. 2 presents an econometric model of the unemployment rate for the period 1980 to 2001. It describes how unemployment reacted to wage changes over that period and the large initial wages overhang that had been created in the nineteen seventies and is similar to the model used in Valentine (1993).

The model includes an equation explaining profits (gross operating surplus) so that the impact of wage changes on different components of GDP can be taken into account. This is consistent with the view that governments attempt to change wage rates as a way of making income distribution more equitable. The GDP identity also fulfils the requirement of Webster (2003) that demand should be endogenous. Participants in the debate on the effect of real wages on the unemployment rate often refer to the impact of wages on aggregate demand. In particular, it is sometimes argued that an increase in wages increases aggregate demand and therefore has a minimal effect on unemployment. All other things equal, an increase in wage rates will increase aggregate wages, but it is also likely to reduce profits. Also, it should be remembered that the ultimate impact of an increase in wage rates on aggregate wages depends in part on the impact of the change on employment.

In pre-analysis of the data it was found that most of the series were integrated of order one in levels, but integrated of order zero in first differences. The price variable is an exception. It comes closest to being integrated at level zero in level terms (the hypothesis of the presence of a unit root is only just accepted at the 10 per cent significance level). 
These results led to the adoption of the following strategy. The equations for the unemployment rate and gross operating surplus are estimated in first differences while the price equation is estimated in level terms. In addition, the residuals of all three equations have been tested for the presence of a unit root using the significance levels given in Table 20.2 of Davidson and Mackinnon (1993). In all three cases the hypothesis of the presence of a unit root is clearly rejected.

A number of writers have suggested reasons for an unstable relationship between the unemployment rate and real wages. They include:

- Henry (2003) who pointed out the growing number of government support recipients who are Disability Support Pensioners and who therefore are not counted as unemployed. Gregory and Cai (2003) made the same point;

- Wooden (2003) who argued that enterprise bargaining has led to increasing productivity being passed onto workers in the form of higher wages and this means that a change in earnings might not have the same effect on unemployment; and

- Gregory and Cai (2003) who pointed out that there has been a shift from fulltime to casual employment in the workforce. Again, this means that a given increase in average earnings has a different effect on recorded unemployment.

However, the coefficients in the equations reported in Table A.2 are very stable and there is little evidence of instability in the relationships.

Table A. 2 omits various identities used in the actual calculations, specifically those relating:

- changes in variables to the levels of those variables; and

- the values of variables to the logarithms of those variables.

Once again the equations have been estimated using the SUR estimator. The correlation matrix for the residuals in the three equations is:

$\begin{array}{llll}\Delta \log \mathrm{UR} & 1.000 & 0.064 & 0.441 \\ \log \mathrm{P} & 0.064 & 1.000 & -0.194 \\ \Delta \log (\mathrm{GOS} / \mathrm{P}) & 0.441 & -0.194 & 1.000\end{array}$

This matrix shows that some gains in the efficiency of the estimates have been achieved. 
Table A.2: A Simple Model of Unemployment 1980-2001

\begin{tabular}{|c|c|}
\hline$\Delta \log U R$ & 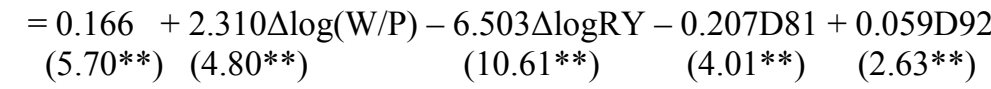 \\
\hline & $\begin{array}{l}\overline{\mathrm{R}}^{2}=0.870 \\
\mathrm{~d}=2.73\end{array}$ \\
\hline $\log \mathrm{P}$ & $\begin{aligned}= & 0.441+0.619 \log \mathrm{P}_{-1}+0.446 \log \mathrm{ULC}-0.0071 \mathrm{UR}+0.0037 \mathrm{t} \\
& \left(5.48^{* *}\right)\left(7.76^{* *}\right) \quad\left(4.50^{* *}\right) \quad\left(4.05^{* *}\right) \quad\left(3.07^{* *}\right) \\
& \overline{\mathrm{R}}^{2}=0.998 \\
\mathrm{~d}=1.44 & \end{aligned}$ \\
\hline$\Delta \log (\mathrm{RGOS})$ & 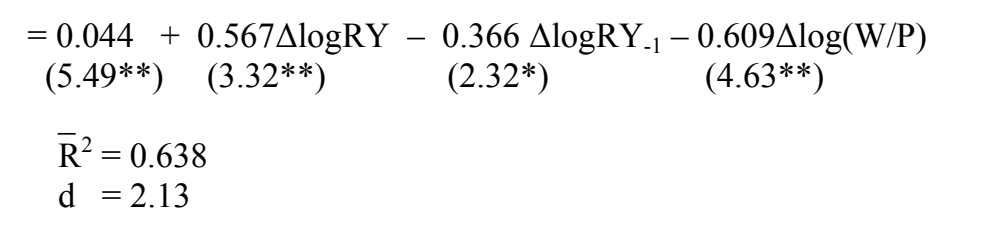 \\
\hline $\begin{array}{l}\text { WSS } \\
\text { EMP } \\
\text { GDP } \\
\text { RY } \\
\text { ULC }\end{array}$ & $\begin{array}{l}=\mathrm{W}^{*} \mathrm{EMP} \\
=\mathrm{WF}(1-\mathrm{UR} / 100) \\
=\mathrm{GOS}+\mathrm{WSS}+\mathrm{X} \\
=\mathrm{GDP} / \mathrm{P} \\
=W S S / R Y\end{array}$ \\
\hline$\underline{\text { Variables }}$ & \\
\hline $\begin{array}{l}\text { D81 } \\
\text { D92 } \\
\text { GDP } \\
\text { EMP } \\
\text { GOS } \\
\text { P } \\
\text { RY } \\
\text { t } \\
\text { ULC } \\
\text { UR } \\
\text { WF } \\
\text { WSS } \\
\text { X }\end{array}$ & $\begin{array}{l}=1 \text { in } 1981 ; 0 \text { otherwise } \\
=1 \text { in } 1992 ; 0 \text { otherwise } \\
=\text { gross domestic product } \\
=\text { employment } \\
=\text { gross operating surplus } \\
=\text { implicit GDP deflator } \\
=\text { GDP at constant prices } \\
=\text { trend starting in } 1980 \\
=\text { unit labour costs } \\
=\text { unemployment rate } \\
=\text { workforce } \\
=\text { wages, salaries and supplements } \\
=\text { other income components of GDP }\end{array}$ \\
\hline
\end{tabular}

Figure A.2 reports the results of dynamic simulations of the model given in Table A.2. UR is the actual value of the unemployment rate and UR* is the value obtained from a dynamic simulation of the model using the actual variables. Although there is a slight tendency to overestimate UR, the model tracks its movements very well. The correlation coefficient between UR and UR* is 0.958 . 
$\mathrm{UR}^{* *}$ shows the effect of increasing wages by 10 per cent over the period. In this case the immediate effect is a reduction in UR because of the positive effect on income.

However, this positive effect is reversed the following year and for the remainder of the period UR is higher. Once again, the effect has not worn off by the end of the period. This outcome arises from similar sources to those identified in the previous subsection (although in this case the long-run elasticity of prices with respect to ULC is not significantly different from unity), but in addition there is a negative impact on profits, which reduces income and, therefore, increases the unemployment rate.

Figure A.2: Simulations of a Model of Unemployment 1980-2001
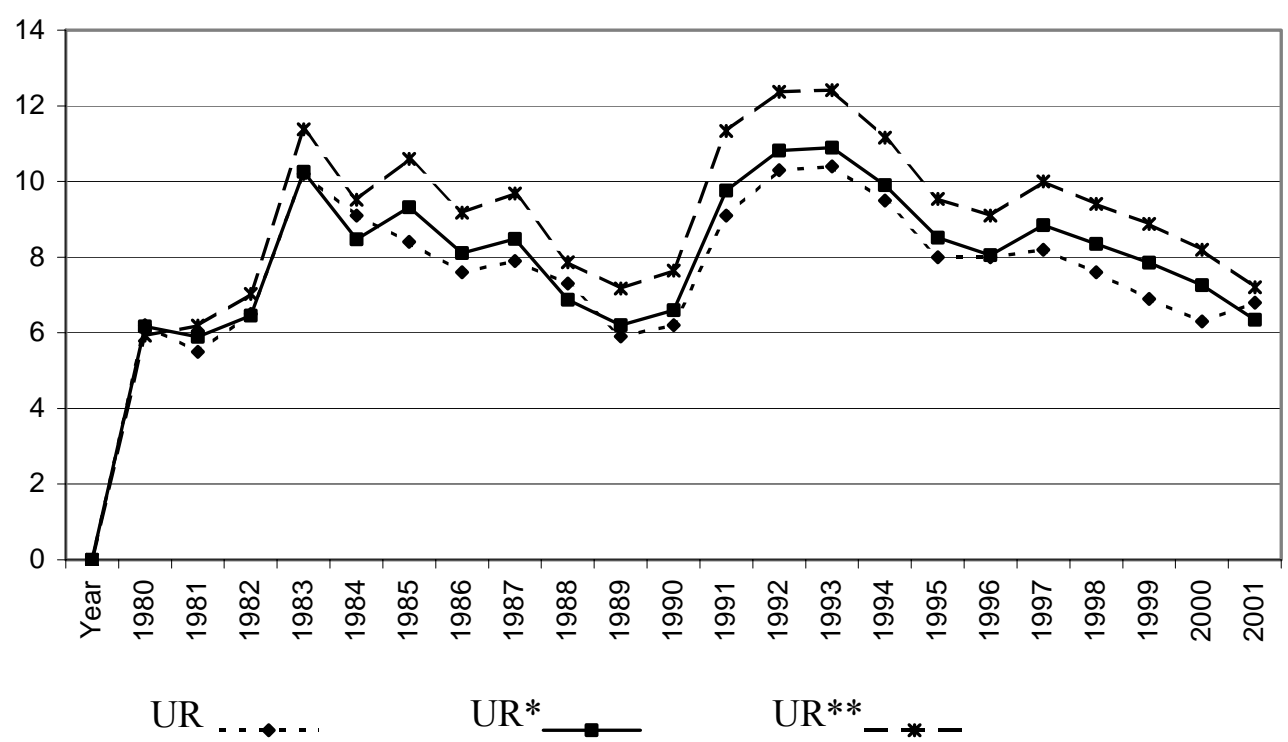

\section{References}

Bell, S. (2000), The Unemployment Crisis in Australia: Which Way Out?, Cambridge University Press, Cambridge.

Butlin, M. (1977), 'A Preliminary Annual Database 1900/01 to 1973/74', Research Discussion Paper No. 7701, Reserve Bank of Australia.

Davidson, R. and J. Mackinnon (1993), Estimation and Inference in Econometrics, Oxford University Press, New York.

Freebairn, J. (2003), 'Some Long Run Labour Market Effects of the Superannuation Guarantee', Paper presented to the Conference on Superannuation, University of Queensland, 26 November. 
Gregory, R., V. Ho and L. McDermott (1988), 'Sharing the Burden: The Australian Labour Market During the 1930s', pp. 217-243 in R. Gregory and M. Butlin (eds), Recovery from the Depression, Cambridge University Press, Cambridge.

Gregory, R. (2000), 'The Impact of Labour-Market and Economic Reforms in the UK, NZ, Australia and the US' pp. 104-124. in Bell (2000), The Unemployment Crisis in Australia: Which Way Out?, Cambridge University Press, Cambridge.

Gregory, R. and L. Cai (2003), 'Our Real and Stubborn Social and Economic Crisis', Paper presented to the 2003 Economic and Social Outlook Conference, Melbourne, 13-14 November.

Henry, K. (2003), 'The Intergenerational Report - 18 Months On', Address to the 2003 Economic and Social Outlook Conference, Melbourne, 13-14 November.

Junankar, P. (2000), 'Are Wage Cuts the Answer? Theory and Evidence', pp.88-103 in Bell (2000), The Unemployment Crisis in Australia: Which Way Out?, Cambridge University Press, Cambridge.

Nevile, J. (2000), 'Can Keynesian Policies Stimulate Growth in Output and Employment?', pp. 149-174 in Bell (2000), The Unemployment Crisis in Australia: Which Way Out?, Cambridge University Press, Cambridge.

Parham, D. (2002), ‘Australia's 1990s Productivity Surge and its Determinants', Paper presented to National Bureau of Economic Research, $13^{\text {th }}$ Annual East Asian Seminar and Economics, 20-22 June.

Quiggin, J. (2000), 'The Public Sector as a Job Engine', pp.211-233 in Bell (2000), The Unemployment Crisis in Australia: Which Way Out?, Cambridge University Press, Cambridge.

Quiggin, J. (2001), 'The Australian Productivity Miracle: A Sceptical View', Agenda 8(4):333-348.

Valentine, T. (1993), 'The Sources of Unemployment: A Simple Econometric Analysis', Economic Papers 12(4):1-20, December.

Valentine, T. (2003), 'The Sterling Exchange Standard in Australia 1900 - 1939', pp. 7998 in M. Lönnborg, M. Olsson, M. Rafferty and I. Nalsen (eds), Money and Finance in Transition, Almqvist and Wiksell, Stockholm.

Webster, E. (2003), 'The Effects of Wages on Aggregate Employment: A Brief Summary of Empirical Studies', The Australian Economic Review 36(1):134-142, March.

Wooden, M. (2003), 'Long-Hours Working and Enterprise Bargaining', Agenda 10(3):259-271.

The author is grateful for the helpful comments of two referees. 